\title{
Pneumoperitoneum Low Volume as Control of Post Surgical Pain
}

\section{Araujo-López Adan ${ }^{1, *}$, González-Rodríguez Mónica ${ }^{1}$, Aburto-Fernández María del Carmen ${ }^{1}$, Herrera-Barrón Sergio Javier ${ }^{2}$, Insunza-Miranda Jesús Giovanni², and Sierra-Brozon Ana Gabriela ${ }^{3}$}

${ }^{1}$ General Surgeon, Department of General Surgery and Gynecologic Laparoscopy, Queretaro General Hospital, General Hospital of Mexico, Hospital of San Juan Del Río, Mexico

${ }^{2}$ General Surgery Resident, Department of General Surgery and Gynecologic Laparoscopy, Queretaro General Hospital, General Hospital of Mexico, Hospital of San Juan Del Río, Mexico

${ }^{3}$ Gynecologist and Obstetrician, Department of General Surgery and Gynecologic Laparoscopy, Queretaro General Hospital, General Hospital of Mexico, Hospital of San Juan Del Río, Mexico

*Corresponding author: Araujo-López Adan, General Surgeon, Department of General Surgery and Gynecologic Laparoscopy, Queretaro General Hospital, General Hospital of Mexico, Hospital of San Juan Del Río, Mexico, Tel: +52 (444) 4 49 12 03; E-mail: draraujolopez@gmail.com

Received: 11 Dec, 2019 | Accepted: 22 Jan, 2020 | Published: 28 Jan, 2020

Citation: Araujo-López A, González-Rodríguez M, Aburto-Fernández MD, Herrera-Barrón SJ, Insunza-Miranda JG, et al. (2020) Pneumoperitoneum Low Volume as Control of Post Surgical Pain. J Surg Open Access 6(2): dx.doi.org/10.16966/2470-0991.206

Copyright: (C) 2020 Araujo-López A, et al. This is an open-access article distributed under the terms of the Creative Commons Attribution License, which permits unrestricted use, distribution, and reproduction in any medium, provided the original author and source are credited.

\section{Abstract}

Introduction: At present, laparoscopic cholecystectomy is considered the procedure of choice in the management of symptomatic cholelithiasis. It has been proposed that pneumoperitoneum in laparoscopic surgery increases post-surgical pain and produces adverse physiological effects in some patients.

Objective: Control postoperative pain in surgery by reducing pneumoperitoneum pressure.

Material and Methods: Study 3 Hospitals, both public and private, comparing the conventional technique using the original intra-abdominal pressure versus lowering the pneumoperitoneum pressure to $10 \mathrm{mmHg}$, to reduce pain.

Conclusion: Reducing the $\mathrm{CO}_{2}$ pressure in $\mathrm{mmHg}$ up to 10.9 on average of the transoperative pneumoperitoneum, was shown as a safe, uncomplicated pressure and reduced postoperative pain without the need to scale up a greater number of analgesics.

Keywords: Pneumoperitoneum; Post-surgical pain; Laparoscopic surgery

\section{Introduction}

Laparoscopic cholecystectomy is currently considered the procedure of choice in the management of symptomatic cholelithiasis. It has been proposed that pneumoperitoneum in laparoscopic surgery increases post-surgical pain and produces adverse physiological effects in some patients [1].

Because peritoneal insufflation decreases venous return and reduces cardiac output, it poses a hazard in patients with low cardiac reserve [2].

Some studies have shown potential advantages with routine use of low pressures to keep pneumoperitoneum in the practice of laparoscopic cholecystectomy [2].

There is no general agreement on the pressure at which pneumoperitoneum should be maintained. Three already published prospective and random studies significantly show lower post-surgical and scapular pain with conversion rates and similar complications when laparoscopic cholecystectomy is performed with low-pressure pneumoperitoneum. On the other hand, some more recent studies than the previous ones find no significant differences in post-surgical pain among patients undergoing low pressure and conventional pressure pneumoperitoneum [1-3].

Recently, the European Association for Endoscopic Surgery published its practical guidelines on pneumoperitoneum for laparoscopic surgery, within which it recommends using the lowest possible intra-abdominal pressure that allows adequate field exposure not to use routine pressure (grade B recommendation) [2].

According to these guidelines, an intra-abdominal pressures less than $14 \mathrm{mmHg}$ is considered safe in a healthy patient (grade A recommendation) [1-3].

Omalgia is a common postoperative adverse event that occurs in 35 to $63 \%$ of cases, usually short-lived and low-intensity with a peak of 24-48 hours after laparoscopic cholecystectomy [4].

The standard pressure used is $12-14 \mathrm{mmHg}$, the low-pressure pneumoperitoneum ranges range from $7-11 \mathrm{mmHg}$ with the attempt to lower the impact of the pneumoperitoneum such as vasovagal reflex, cardiac arrhythmias, acidosis, hypercapnia, minimize the effect hemodynamic and lessen postoperative pain. However, lower pressures could result in limited exposure, leading to increased 
surgical time, standard laparoscopic pressure conversion, or conversion to open cholecystectomy. The current study proposes comparing the advantages of low-volume pneumoperitoneum compared to the standard pressure for postoperative pain management [1-5].

\section{Material and Methods}

The work was carried out with patients from 3 hospitals under different surgeons but in two of them were public hospitals with the original methodology (General Hospital of Querétaro, and Cadereyta), compared to the private medium of a surgeon who was the group of a private hospital (Hospital San José de Querétaro).

The variables of age, sex, comorbidities (diabetes mellitus, high blood pressure and others), Intra-Abdominal Pressure (IAP) (initial, transsurgical), and Complications were studied.

We conducted a Retrospective, Descriptive, Observational study.

Within our study we used a descriptive statistic which was implemented for:

- Quantitative Variables; means and standard deviation, using analysis t-student.

- Qualitative variables were used frequencies and percentages. Using analysis in Chi-square $\left(\mathrm{X}^{2}\right)$.

- The SPSS V.21 program was used. The results were reflected in tables and graphs.

Based on the general characteristics, we can observe that our $\mathrm{n}$ was 82 patients, in whom we observed that we had the greatest number of females intervened, without associated comorbidities, predominant diagnoses of chronic cholecystitis, presenting a $5.8 \mathrm{~mm}$ Visual Analogue Scale (VAS) apparently (Table 1).

Based on the clinical characteristics we can see that we obtained significant difference of 0.006 based on the fellows, so we can also see that during the entry of the surgery the intra-abdominal pressure showed significant difference of 0.001 , average patients with intrabdominal $\mathrm{CO}_{2}$ pressure management with a significant difference of 0.004 (Table 2).

We got a significant difference based on the lower pressure in $\mathrm{mmHg}$ of $\mathrm{CO}_{2}$ we use, better post-surgical evolution will be based on post-surgical pain, based on the VAS scale, we have shown that if there is a difference statistically significantly of a $\mathrm{p}=0.002$.

In this graph 1 we can find the comorbidities found in each group, i.e. patients who had comorbidities were lower in the control group (17.5), compared to patients who intervened with lower pressure but more percentage of incidence of comorbidities (48) giving us less bias to false negatives.

The graph of calms based on the control groups, we can see that we had a higher presence rate on patients with Diabetes Mellitus type 2, and Systolic Arterial Hypertension, with predominance over the patients in the study group with the Low-control pneumoperitoneum, which means that even with neuropathy the pain was shown in a smaller proportion (Graph 2).

During the study, we performed analyses based on initial cavity insufflation with $14 \mathrm{mmHg}$ in all our patients, both the control and comparative group, where we can observe that the average pressure of trans-surgical $\mathrm{CO}_{2}$ was $10.9 \mathrm{mmHg}$, indicating that if they were $\pm 4 \mathrm{mmHg}$, by difference they have shown an improvement in pain in the group that if it was manipulated by the surgeon for pain control, getting significant difference from it (Graph 3).
Table 1: Comparison of variables of age, sex, comorbidities (diabetes mellitus, high blood pressure and others), Intra-Abdominal Pressure (IAP) (initial, transsurgical), and Complications.

\begin{tabular}{|c|c|}
\hline Variable & $\mathrm{N}=82$ \\
\hline \multicolumn{2}{|l|}{ Gender } \\
\hline Man & $16(19.5)$ \\
\hline Woman & $66(80.5)$ \\
\hline Age & $39.7 \times 15.2$ \\
\hline \multicolumn{2}{|l|}{ Comorbidities } \\
\hline Yes & $22(26.8)$ \\
\hline No & $60(73.2)$ \\
\hline DM & $14(17.1)$ \\
\hline HBP & $10(12.2)$ \\
\hline $\mathrm{AF}$ & $1(1.2)$ \\
\hline Urolithiasis & $1(1.2)$ \\
\hline Liver Disease & $3(3.7)$ \\
\hline \multicolumn{2}{|l|}{ Diagnosis } \\
\hline $\mathrm{CCL}$ & $57(69.5)$ \\
\hline CCL+Pyocolecyst & $2(2.4)$ \\
\hline $\mathrm{CCL}+$ Hydrocholeystis & $11(13.4)$ \\
\hline Liver cyst & $1(1.2)$ \\
\hline Liver abscess & $1(1.2)$ \\
\hline $\mathrm{CCL}+$ Choledocholithiasis & $10(12.2)$ \\
\hline \multicolumn{2}{|l|}{ Surgery } \\
\hline Laparoscopic cholecystectomy & $74(96.3)$ \\
\hline Laparoscopic drainage & $2(2.4)$ \\
\hline $\begin{array}{l}\text { Laparoscopic Cholecystectomy+Col } \\
\text { angiography+bile duct exploration }\end{array}$ & $1(1.2)$ \\
\hline START IAP (mmHg) & $13.97 \times 0.22$ \\
\hline IAP during surgery $(\mathrm{mmHg})$ & $13.06 \times 1.58$ \\
\hline Average IAP (mmHg) & $12.86 \times 0.43$ \\
\hline Post-surgical pain & $5.8 \times 2.11$ \\
\hline
\end{tabular}

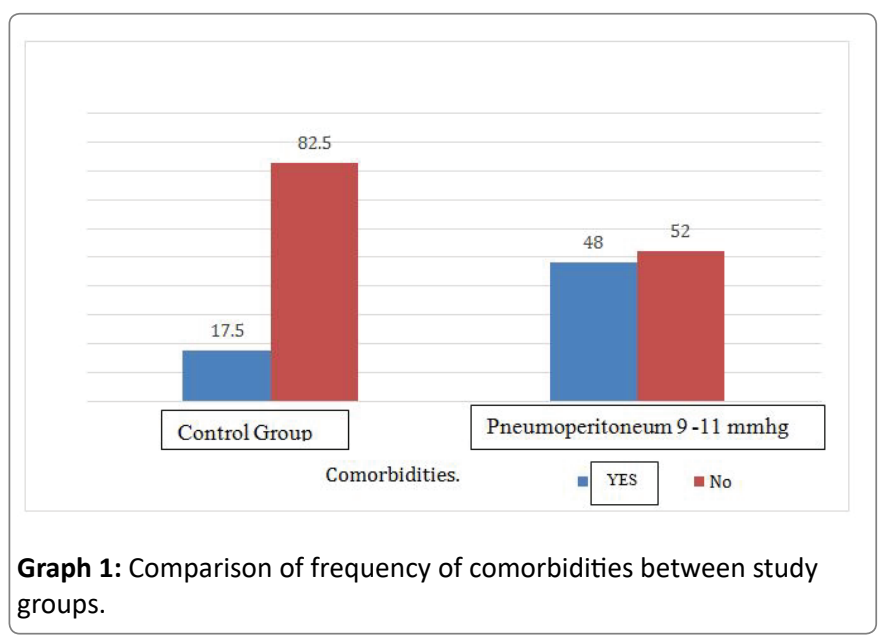

The complete significant difference of this study was obtained under the criterion of the particular objectives of the study, i.e. we got a significant difference with a p-0.002, where we can say that the lower pressure handled the $\mathrm{CO}_{2}$ as pneumoperitoneum, we can manipulate pain, regardless of placing neuromuscular blockage or not, being this repeatable and transmissible after generational, implemented in the study (Graph 4). 
Table 2: Comparison of classic group features.

\begin{tabular}{|c|c|c|c|}
\hline Variable & $\begin{array}{c}\text { Control } \\
n=57\end{array}$ & $\begin{array}{c}\text { Pneumoperitoneum } \\
\text { 9-11 } \mathrm{mmHgn}=25\end{array}$ & $Q$ \\
\hline \multicolumn{4}{|l|}{ Gender } \\
\hline Man & $11(19.3)$ & $5(20)$ & \multirow{2}{*}{0.581} \\
\hline Woman & $46(80.7)$ & $20(80)$ & \\
\hline Age & $38.8 \times 14.2$ & $41.5 \times 17.6$ & 0.506 \\
\hline \multicolumn{4}{|l|}{ Comorbidities } \\
\hline Yes & $10(17.5)$ & $12(48)$ & \multirow{2}{*}{0.006} \\
\hline No & $47(82.5)$ & $13(52)$ & \\
\hline DM & $8(14)$ & $6(24)$ & 0.213 \\
\hline HBP & $5(8.8))$ & $5(20)$ & 0.114 \\
\hline$A F$ & $0(0)$ & $1(4)$ & 0.305 \\
\hline Urolithiasis & $0(0)$ & $1(4)$ & 0.305 \\
\hline Liver Disease & $1(1.8)$ & $2(8)$ & 0.219 \\
\hline \multicolumn{4}{|l|}{ Diagnosis } \\
\hline $\mathrm{CCL}$ & $39(68.4)$ & $18(72)$ & \multirow{6}{*}{0.648} \\
\hline CCL+Pyocolecyst. & $0(0)$ & $2(18)$ & \\
\hline $\mathrm{CCL}+\mathrm{Hydrocholeystis}$ & $9(14)$ & $3(12)$ & \\
\hline Liver cyst & $0(0)$ & $1(4)$ & \\
\hline Liver abscess & $0(0)$ & $1(4)$ & \\
\hline CCL+Choledocholithiasis & $10(17.5)$ & $0(0)$ & \\
\hline \multicolumn{4}{|l|}{ Surgery } \\
\hline $\begin{array}{l}\text { Laparoscopic } \\
\text { cholecystectomy }\end{array}$ & $57(100)$ & $22(88)$ & \multirow[b]{3}{*}{0.782} \\
\hline Laparoscopic drainage & $0(0)$ & $2(8)$ & \\
\hline $\begin{array}{l}\text { Laparoscopic } \\
\text { Cholecystectomy + } \\
\text { Cholangiography+Bile } \\
\text { Duct Exploration }\end{array}$ & $0(0)$ & $1(4)$ & \\
\hline START IAP (mmHg) & $14 \times 0.01$ & $13.9 \times 0.4$ & 0.132 \\
\hline $\begin{array}{l}\text { IAP during surgery } \\
(\mathrm{mmHg})\end{array}$ & $14 \times 0.0$ & $10.9 \times 1.2$ & $<0.001$ \\
\hline Average IAP (mmHg) & $13 \times 0.0$ & $12.6 \times 0.7$ & 0.004 \\
\hline Post-surgical pain & $6.2 \times 1.92$ & $4.7 \times 2.1$ & 0.002 \\
\hline
\end{tabular}

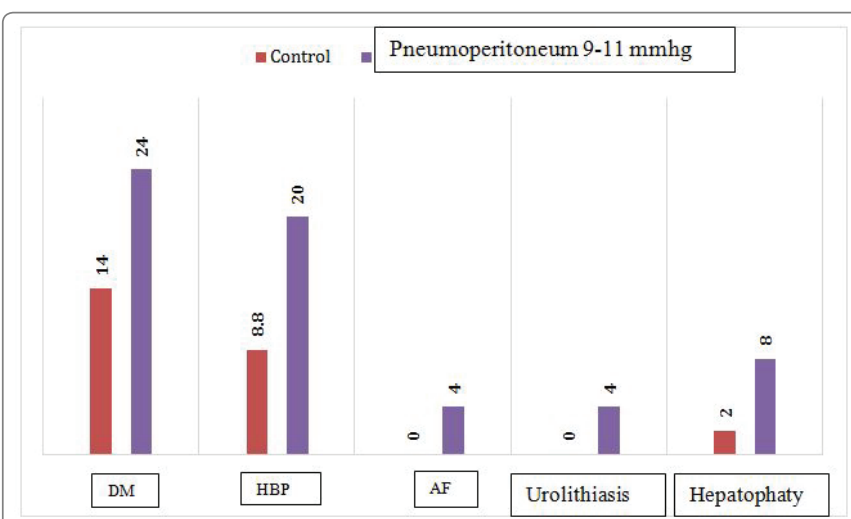

Graph 2: Comparison of percentage of comorbidities between study groups.

DM: Mellitus Diabetes; HBP: High Blood Pressure; AF: Atrial Fibrillation

\section{Discussion}

\section{Anatomic considerations of the biliar vescule}

The gallbladder is an organ that in the adult is pear-shaped, a length of between 7 and 10 centimeters and diameter of 3 to $5 \mathrm{~cm}$. Occupies

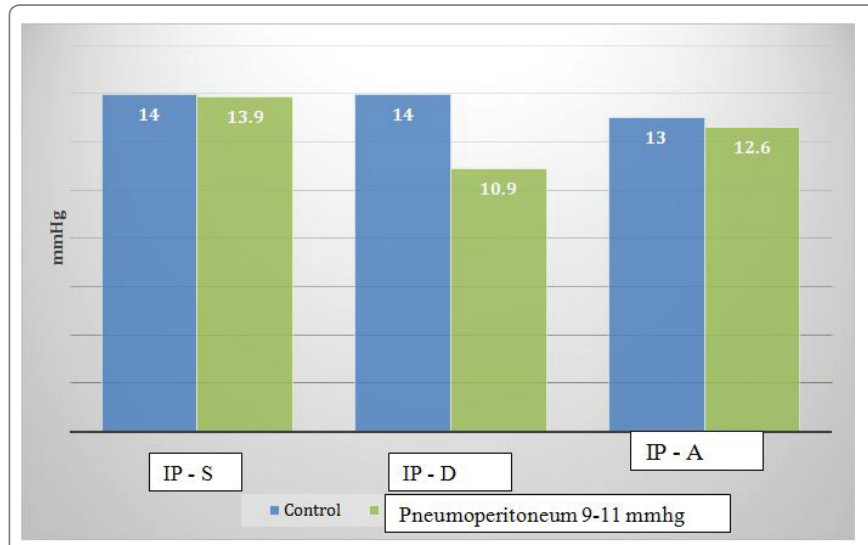

Graph 3: Comparison of pressures (induced pneumoperitoneum) during initiation and transsurgical.

IPL: Intrabdominal Pressure; S: Start; D: During; A: Average

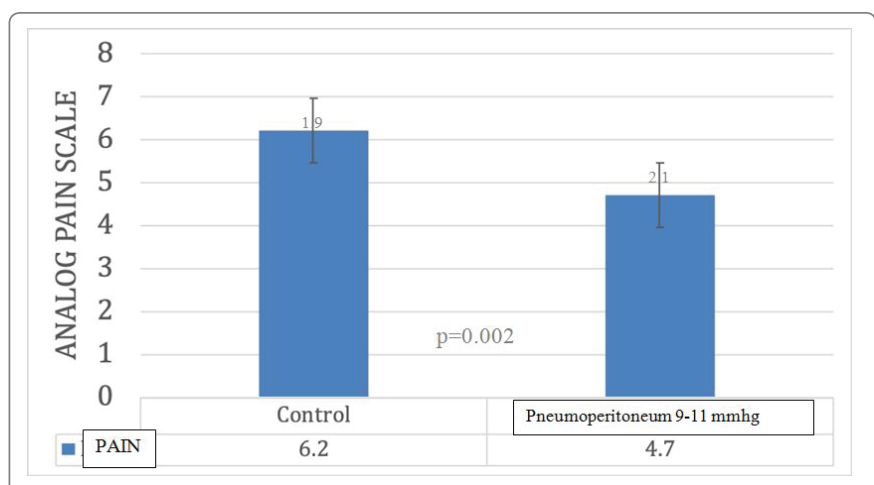

Graph 4: Difference of postoperative pain in groups of patients with pneumoperitoneum handling at $10.9 \mathrm{mmHg}$ average versus control group.

the gallbladder pit of the visceral face of the liver, at the level of the right lobe, at the junction of the middle third with the two lateral thirds of the front edge [1].

It has three parts: The bottom, the body and the neck. The bottom is usually located at the level of the ninth right rib cartilage, at the level of the middle clavicular line. The body is in close contact with the second portion of the duodenum and colon. The neck is directed towards the hepatic hilum, the cystic duct is continued. It binds with the common liver duct to form the common bile duct or bile duct, which measures about $15 \mathrm{~cm}$ long [1].

The gallbladder is not entirely surrounded by peritoneum, only the bottom has a complete peritoneal coating, which describes above the all recess. The body is peritoneum covered in lower and lateral faces, and from there the peritoneum is reflected on the surface of the liver. At the neck level, the peritoneum forms a meso, which is inserted into the lower face of the liver and is called meso cyst. It is often extended to flow to form the hepatologic ligament [2].

The irrigation of the gallbladder is provided by the cystic artery, which also irrigates the cystic duct. Usually this artery originates from the right hepatic artery, at an angle formed between the common liver duct and the cystic duct; this space is called the Calot triangle or hepatocytic triangle. From its origin, the cystic artery is directed crosswise to the right, passing to the right (or backward or front) of the common liver duct. 
This artery gives two branches: One anterior and one posterior, both surrounding the gallbladder [1-3].

The cystic veins take care of the venous drainage of both the neck of the gallbladder and the cystic duct. These veins enter directly into the liver or drain into the portal vein. In the case of the body and background, they have veins that pass directly to the visceral face of the liver and drain liver sinusoids [3].

Lymphatic drainage originates in the sub mucosal networks and is directed towards the cystic ganglia, which is located at the neck level of the gallbladder, and to the nodes of the liver root. From there they are heading to drain into the celiac nodes. The gallbladder and cystic duct are inert by nerves that come in conjunction with the cystic artery from the celiac plexus, which provides the sympathetic and visceral afferent fibers for pain. In addition, there is input of the vagus nerve for parasympathetic regulation and the right phrenic nerve, which corresponds to the somatic fibers [4].

Typically, the gallbladder has a storage capacity of approximately 30 to 60 milliliters. However, when you are actively reabsorbing water, sodium, chlorine, and other electrolytes continuously, up to $450 \mathrm{ml}$ of secretion can be stored [4].

\section{Abnormal position of the biliary vesicle}

Anatomical variations in the gallbladder are common. They do not involve pathology; however, they can hinder surgery predisposing to cause iatrogenic biliary. It is therefore important to consider this possibility before developing a surgical procedure $[1,3,4]$. Some of the most important anatomical variants are:

Osminous gallbladder: (vesicle to the left of the round ligament). It may be on the left (when the liver is in normal anatomical position is asymptomatic), may be intrahepatic (due to the ectopic appearance of the sketch), back-right, retroperitoneal, transverse or suprahepatic [1-5].

Gallbladder with frigid cap: is a clinically innocuous entity consisting of a partial or complete septum (or fold) that separates the bottom and body from the gallbladder, due to a defect in the pipeline at twelve weeks. It is one of the most common anatomical variants $[1,6]$.

Double gallbladder: The double gallbladder term implies a duplication of the term in which there are two independent cavities and two separate cystic ducts, which can flow separately or meet previously forming an inverted "Y". It is a rare variant of the bile system with a frequency of 1 in every 4000 cases and can be detected preoperatively by imaging studies. Vesicular duplication has a prevalence of 2.5 in 10000 autopsy studies and approximately 200 cases reported in the literature. It is important to note that in most reported cases the diagnosis is made in cadaver studies [1,7].

Double cystic duct: The presence of a cystic duct is associated with up to $80 \%$ of cases with a double gallbladder, however it may occur with a single gallbladder in fewer cases. The vast majority of cystic duct malformations have no clinical significance, taking on importance when identified either with imaging studies or predominantly incidentally during a surgical procedure, it is vital identification to prevent iatrogenesis of this structure $[1,8]$.

\section{Laparoscopic cholecystectomy}

Laparoscopic cholecystectomy is performed with the patient in supine decubitus and with the surgeon located to the patient's left and in front of the monitor. There are several laparoscopic cholecystectomy techniques, including multiple incision (MILS, per multi-incision laparoscopic surgery), single incision (SILS, by single-incision laparoscopic surgery) and transluminal by hole (NOTES, by natural orifice transluminal surgery) [1,9-16].

\section{MILS}

It corresponds to the classical technique that was developed in the late 1980s. The procedure begins with the establishment of a pneumoperitoneum, which consists of a workspace that is created by inflating a gas into the peritoneal cavity. There are 2 techniques for establishing pneumoperitoneum: one is the closed technique, in which the peritoneal cavity is accessed "blindly"; the other is the open technique, in which the peritoneal cavity is accessed under direct visualization. In the closed technique, a supraumbilical or infraumbilical incision is made in the superficial abdominal tissues and through it a Veress needle is inserted. In the open technique, a supraumbilical or infraumbilical incision is made and this is continued in depth through the fascia and the peritoneum. When the peritoneal cavity has been accessed, a Hasson cannula is inserted into it and retaining sutures are made to anchor and secure the cannula to the fascia. The gas is then in soured through the Veress needle or Hasson cannula and pneumoperitoneum is created. Generally, the gas used is carbon dioxide, although nitric oxide, argon and helium have also been used [16].

If the closed technique has been used, once the pneumoperitoneum has been established, a 10 millimeter trocar is introduced for the incision made and this corresponds to the port or umbilical access. If the open technique has been used, Hasson's cannula corresponds to the port or umbilical access. Through the umbilical port, the laparoscope is inserted and the abdomen is inspected, especially the gallbladder region. A $10 \mathrm{~mm}$ trocar is then inserted into the epigastrium, a 5 $\mathrm{mm}$ trocar in the right hypochondriac, approximately on the right midclavicular line, and a $5 \mathrm{~mm}$ trocar on the right flank, approximately on the right anterior axillary line [16]

Through the trocars the surgical instrument is inserted, the gallbladder is resected and finally it is extracted through the umbilical port of the epigastrium port [17].

\section{SILS}

The past two decades have meant a revolution in the field of minimally invasive surgery. As part of this revolution, a laparoscopic cholecystectomy technique was developed in the late 1990s and is called SILS. In this case, different incisions are made in the fascia in the same umbilical incision and the trocars are inserted through them. The main objective of replacing the MILS technique with SILS is to minimize the invasive nature of the procedure, which theoretically minimizes postoperative pain, the length of the hospital stay and the recovery time, at the same time that optimizes aesthetics. However, it is usually associated with longer operative time. It has been shown to be a safe technique and an acceptable alternative to the MILS technique, and studies suggesting that it effectively reduces hospital stay and recovery time in comparison to MILS technique [17].

\section{NOTES}

As part of the revolution in the field of minimally invasive surgery, a new focus has also been developed on endoscopic surgery that is performed by inserting an endoscope through an external hole, such as the mouth, anus, vagina or urethra, to access the different body cavities and is called NOTES. The use of the NOTES technique also aims to minimize the invasive nature of the procedure. Among the advantages for which the procedure stands out are the reductions 
of post-operative pain, the decrease of the analgesia required for the operation, the decrease in recovery time. In addition, avoiding superficial incisions prevents visible scars, further aesthetics [17].

The first human cholecystectomy using the NOTES technique through the transvaginal approach was reported in 2007 and through the transgastric approach in 2008. Transvaginal approach is considered the preferred approach because it eliminates the risk of leakage of intestinal content and because various records have shown an association between this approach and a low rate of complications. Finally, the transcolonic approach to access the peritoneal cavity has been little explored due to the possibility of fecal contamination and intra-abdominal infectious complications; however, cases of cholecystectomy have been reported following this technique [18].

\section{Physiological effects of laparoscopic surgery}

The magnitude of the cardiovascular effects associated with laparoscopy will depend on the interaction of several factors including the patient's position the intraabdominal pressures obtained during the creation of pneumoperitoneum, the effects neurohumoral $\mathrm{CO}_{2}$ absorption, prior cardiovascular status, intravascular volume, ventilation technique and anesthetic agents used [17].

Most studies describe an increase in mean blood pressure, systemic vascular resistances and cardiac filling pressures, accompanied by a decrease in heart rate and changes in heart rate $[16,18]$. Intentional hypercapnia under anesthesia increases cardiac output, average blood pressure, heart rate, and plasma concentrations of catecholamines. Systemic vascular resistances decrease and reflect the direct vasodilator effects of $\mathrm{CO}_{2}$, when these are not counteracted by the activation of the sympathetic nervous system that constricts venous capacitance vessels $[18,19]$.

In any laparoscopic procedure, the gas peritoneal cavity is insufflated $\mathrm{CO}_{2}$ is the most commonly used gas for its high diffusion, rapid disposal and low cost. Carboperitoneum separates the abdominal wall from the organs to allow visual access. Modern insufflators release the gas with flows of two to $10 \mathrm{l} / \mathrm{min}$. Intraabdominal Pressure (IAP) of up to $15 \mathrm{mmHg}$ is considered suitable for most upper abdomen surgical procedures. With this intra-abdominal pressure, in young patients and without concomitant disease, $\mathrm{CO}_{2}$ retention is minimal. However, in subjects with cardiopulmonary disease, during carboperitoneum, absorption is greater and the hemodynamic and pulmonary effects of $\mathrm{CO}_{2}$ are more significant [19].

Carboperitoneum, elevated intraabdominal pressure, hypercapnia and position changes during laparoscopic surgery induce cardiopulmonary, renal, liver, cerebral and metabolic effects, which can complicate anesthetic management $[18,19]$.

There are studies of hemodynamic changes in ASA I. Lackey, et al. patients, reports results during laparoscopic cholecystectomy with the use of invasive pulmonary arterial catheter monitoring at an intraabdominal pressure of $14 \mathrm{mmHg}$. Induction of anesthesia lowers Mean Blood Pressure (MAP) and Heart Index (HF). Changing the position to inverted Trendelenburg reduces Right Atrium Pressure (RAP), wedge Pulmonary Capillary Pressure (PCPC) and preload. Peritoneal insufflation increases mean blood pressure, Systemic Vascular Resistance (SVR) and Pulmonary Vascular Pressure (RVP), right atrium pressure and wedge pulmonary capillary pressure, with no changes in Heart Rate (HR). The combination of the effects of anesthesia, insufflation and position result in a decrease in $50 \%$ of the heart rate [18].

On the other hand, pneumoperitoneum by causing an increase in intra-abdominal pressure, will influence the chest cavity by elevation of the diaphragms, which in turn causes physiological disorders such as: decreased pulmonary compliance, decrease in residual functional capacity, increased Blood Pressure of $\mathrm{CO}_{2}$ and increased alveolar $\mathrm{CO}_{2}$ [19].

Willis, et al. studied lung changes and risks of perioperative complications during laparoscopic cholecystectomy with carboperitoneum at an intra-abdominal pressure of 10 to $15 \mathrm{mmHg}$ in ASA I patients. During insufflating, changes in lung parameters including Minute Volume (VM), Peak Inspiring Pressure (PIP) and final expiratory $\mathrm{CO}_{2}$ fraction were obtained. In patients with lung and/ or cardiovascular disease, the proper exchange of gas is prevented, with impaired $\mathrm{CO}_{2}$ absorption, and hypercapnia occurs. $\mathrm{PaCO}_{2}$ rises significantly more than $\mathrm{FEFCO}_{2}$, indicating increased lung dead space. To maintain $\mathrm{PaCO}_{2}$ between $3042 \mathrm{mmHg}$, Respiratory Rate (FR), VC, and intra-abdominal pressure are continuously adjusted $[17,18]$.

Manipulation of parietal peritoneum and abdominal viscera after pneumoperitoneum may result in vagal stimulation that triggers the reflexes of nausea, vomiting and bradycardia. Vomiting is the most common complication, especially in obese patients. Preoperative anxiety, gastric bloating, opioid administration, nitrous oxide, inhaled anesthetics and the reversal agent, neostigmine, may be involved in the onset of nausea and vomiting that aggravate the effect facilitator of emesis that produce the pneumoperitoneum and the position of Trendelenburg [20].

Although one of the advantages of laparoscopic surgery is the decrease in pain, this complication usually occurs after this type of procedure and after surgery $\mathrm{CO}_{2}$ tends to accumulate in the sub diaphragmatic and irritate the phrenic nerve spaces this one for metameres will cause pain at the level of the shoulders and back from which patients complain. This pain usually calms spontaneously after several hours while $\mathrm{CO}_{2}$ is absorbed, however, nonsteroidal painkillers such as Ketoprofen, Ketorolaco among others have been used to alleviate the patient's complaint. A technique advocated by some anesthesiologists is to give oxygen $100 \%$ half an hour after the pneumoperitoneum has been removed to ensure that no carbonic gas is left in the peritoneal cavity [18].

Wahba et al. propose that the pain is of less intensity and shorter duration than that of a laparotomy, occurs essentially in the abdomen, back and shoulders. The frequency of presentation ranges from $35 \%$ to $63 \%$ of patients and can last up to three days [17-20].

Pain in a subjective sensation and its measurement and analysis are difficult. The visual analog scale of pain, presented as a $10 \mathrm{~cm}$ horizontal bar, is simple, feasible and valid, as it reflects the degree of intensity of the pain in the heart of its evaluation, making it a useful tool to describe the pain. Compared to other scales, it is thought to be more sensitive for detecting small differences in pain levels.

On the other hand, post-surgical scapular pain, practically inherent or typical of laparoscopic surgery, is a common phenomenon (30$50 \%$ ) and annoying, its etiology and pathogenesis have not been entirely designed, so there are multiple theories to try to explain its origin. To date, the proposed mechanisms include a) Diaphragmatic and abdominal cavity overvoltage, b) Irritation of the diaphragmatic endings of the phrenic nerve due to carbonic acid formed from the insufflated $\mathrm{CO}$, theory supported by the fact that scapular pain decreases if nitrous oxide is insufflated instead of $\mathrm{CO}_{2}, \mathrm{c}$ ) The activation of the sympathetic nervous system derived from hypercarbia leading to amplification of the local tisular inflammatory response as well as to the ischemia of the splenic mucosa and d) Mechanical irritation imposed by drains [18]. 
Some studies have shown potential advantages with routine use of low pressures to keep pneumoperitoneum in the practice of laparoscopic cholecystectomy. Recently, the European Association for Endoscopic Surgery published its practical guidelines on pneumoperitoneum for laparoscopic surgery, within which it recommends using the lowest possible intra-abdominal pressure that allows for adequate exposure and not use routine pressure (grade B recommendation). According to these guidelines, an intra-abdominal pressure less than $14 \mathrm{mmHg}$ is considered safe in a healthy patient (grade A recommendation) and wall lifting devices do not show relevant clinical advantages compared to low pneumoperitoneum pressure [18].

There is no general agreement on the pressure at which pneumoperitoneum should be maintained. Three already published prospective and random studies significantly show lower post-surgical and scapular pain with conversion rates and similar complications when laparoscopic cholecystectomy is performed with low pneumoperitoneum Pressure. On the other hand, some more recent studies than the previous ones do not find significant differences in post-surgical pain among patients undergoing conventional pressure and low-pressure pneumoperitoneum, so they refrain from recommending use of pneumoperitoneum with low intra-abdominal pressure routinely in laparoscopic cholecystectomy [19].

In our work we have a group of 82 individuals undergoing cholecystectomy for symptomatic cholelithiasis mostly women, of whom 57 were treated standard with average pneumoperitoneum of $14 \mathrm{mmHg}$ and 25 who were treated with pneumoperitoneum with pneumoperitoneum with low pressure, where it was found that if there was significant difference in post-surgical pain for the benefit of the low-pressure pneumoperitoneum of $\mathrm{p}-0.002$ which is comparable to what is found in the literature [21-23].

\section{Conclusions}

1. There were no differences in the outcome of emergency surgery and scheduled with low-pressure pneumoperitoneum.

2. There was no significant difference in the intra-abdominal starting pressure in both groups.

3. Decreased postoperative pain in laparoscopic cholecystectomies of low-pressure pneumoperitoneum.

4. No increase in postsurgical complications secondary to low pressure pneumoperitoneum is reported compared to standard pneumoperitoneum.

5. Cholecystectomy with low-pressure pneumoperitoneum has a positive impact on patients' postoperative recovery.

6. It is feasible to perform this type of surgeries with low pressure pneumoperitoneum whenever performed by an experienced surgeon, to also improve surgical times and promote early high.

\section{References}

1. Nematihonar B, Fahimihanzaei H, Kamranmanesh M, Memary E, Shahbazi A, et al. (2017) Comparison Postoperative Shoulder Pain, Nausea, and Vomiting Between Low and Normal Pressure Pneumoperitoneum in Laparoscopic Cholecystectomy. Annals of Anestesic Critic Care 2: 149-151.

2. Gurusamy KS, Koti R, Davidson BR (2013) Abdominal lift for laparoscopic cholecystectomy. Cochrane Database Syst Rev 31: 101106.

3. Strasberg SM, Brunt LM (2010) Rationale and use of the Critical View of Safety in Laparoscopic Cholecystectomy. J Am Coll Surg 211: 132-138.
4. Koc M, Ertan T, Tez M, Kocpinar MA, Kilic M, et al. (2005) Randomized, prospective comparison of postoperative pain in low-versus highpressure pneumoperitoneum. ANZ J Surg 75: 693-696.

5. Nasajiyan N, Javaherfourosh F, Ghomeishi A, Akhondzadeh R, Pazyar F, et al. (2014) Comparison of low and standard pressure gas injection at abdominal cavity on postoperative nausea and vomiting in laparoscopic cholecystectomy. Pak J Med Sci 30: 1083-1087.

6. Kar M, Kar JK, Debnath B (2011) Experience of Laparoscopic Cholecystectomy Under Spinal Anesthesia with Low-pressure Pneumoperitoneum-Prospective Study of 300 Cases. Saudi J Gastroenterol 17: 203-207.

7. Vijayaraghavan $\mathrm{N}$, Sistla SC, Kundra $\mathrm{P}$, Ananthanarayan $\mathrm{PH}$, Karthikeyan VS, et al. (2014) Comparison of Standard-pressure and Low-pressure Pneumoperitoneum in Laparoscopic Cholecystectomy: A Double Blinded Randomized Controlled Study. Surg Laparosc Endosc Percutan Tech 24: 127-133.

8. Schirmer BD, Edge SB, Dix J, Hyser MJ, Hanks JB, et al. (1991) Laparoscopic cholecystectomy. Treatment of choice for symptomatic cholelithiasis. Ann Surg 213: 665-676.

9. Dexter SP, Vucevic M, Gibson J, McMahon MJ (1999) Hemodynamic consequences of high-and low-pressure capnoperitoneum during laparoscopic cholecystectomy. Surg Endosc 13: 376-381.

10. Neudecker J, Sauerland S, Neugebauer E, Bergamaschi R, Bonjer $\mathrm{HJ}$, et al. (2002) The European Association for Endoscopic Surgery clinical practice guideline on the pneumoperitoneum for laparoscopic surgery. Surg Endosc 16: 1121-1143.

11. Barczynski M, Herman RM (2003) A prospective randomized trial on comparison of Low-Pressure (LP) and Standard-Pressure (SP) pneumoperitoneum for laparoscopic cholecystectomy. Surg Endosc 17: 533-538.

12. Serra AS, Lledó JB, Santafé AS, Espinosa RG, Bertomeu CA, et al. (2002) Evolución del dolor postoperatorio en la colecistectomía laparoscópica bajo anestesia-analgesia multimodal en régimen ambulatorio. Rev Esp Anestesiol Reanim 49: 461-467.

13. Davila S, Chavez R (2010) Dolor postoperatorio en colecistectomía laparoscópica. Ropivacaína vs. placebo. Ensayo clínico. Cir Gen 32: 96-99.

14. Olavarrieta JRL (2005) La Irrigación Con Bupivacaina Intraoperatoria En La Prevencion Del Dolor En El Hombro Post Colecistectomía Laparoscópica. Revista Multidisciplinaria del Consejo de Investigación de la Universidad de Oriente 17: 131-138.

15. Claros N, Fuentes I, Cari A, Laguna R (2010) Omalgia Asociada A Neumoperitoneo A Baja Presión vs Presión Estándar Durante La Colecistectomía Laparoscópica. Rev Med La Paz 16: 5-11.

16. López-Maya L, Lina-Manjarrez F, Díaz-Peralta A, Lina-López LM (2011) Disminución del dolor postoperatorio en colecistectomía laparoscópica. Ropivacaína cutánea e intraperitoneal (antes vs después) de la incisión y neumoperitoneo. Rev Mex Anest 34: 251259.

17. Schietroma M, Carlei F, Cecilia EM, Piccione F, Sista F, et al. (2013) A prospective randomized study of systemic inflammation and immune response after laparoscopic nissen fundoplication performed with standard and low-pressure pneumoperitoneum. Surg Laparosc Endosc Percutan Tech 23: 189-196.

18. Basgul E, Bahadir B, Celiker V, Karagoz AH, Hamaloglu E, et al. (2004) Effects of low and high intra-abdominal pressure on immune response in laparoscopic cholecystectomy. Saudi Med J 25: 18881891. 
19. Hua J, Gong J, Yao L, Zhou B, Song Z (2014) Low-pressure versus standard-pressure pneumoperitoneum for laparoscopic cholecystectomy: a systematic review and meta-analysis. Am J Surg 208: 143-150.

20. Donatsky AM, Bjerrum F, Gögenur I (2013) Surgical techniques to minimize shoulder pain after laparoscopic cholecystectomy. A systematic review. Surg Endosc 27: 2275-2282.

21. Royse CF, Chung F, Newman S, Stygall J, Wilkinson DJ (2013) Predictors of patient satisfaction with anaesthesia and surgery care: a cohort study using the Postoperative Quality of Recovery Scale. Eur J Anaesthesiol 30: 106-110.
22. Vijayaraghavan $\mathrm{N}$, Sistla SC, Kundra $\mathrm{P}$, Ananthanarayan $\mathrm{PH}$ Karthikeyan VS, et al. (2014) Comparison of standard-pressure and low-pressure pneumoperitoneum in laparoscopic cholecystectomy: a double blinded randomized controlled study. Surg Laparosc Endosc Percutan Tech 24: 127-133.

23. Warlé MC, Berkers AW, Langenhuijsen JF, Van der Jagt MF, Dooper PhM, et al. (2013) Low-pressure pneumoperitoneum during laparoscopic donor nephrectomy to optimize live donors' comfort. Clin Transplant; 27: E478-E483. 